\title{
The Influence of Materials and Techniques on Art Studios in the Early Renaissance
}

\author{
Bingqing $\mathrm{Wei}^{1{ }^{1, *}}$ \\ ${ }^{1}$ Faculty of Arts, Graduate School of Humanities and Social Sciences, The University of Melbourne, Victoria 3010 \\ Australia \\ *Corresponding author. Email: gyalnrei@163.com
}

\begin{abstract}
During the Renaissance, the progress of painting materials and techniques simplified the steps of artists' creation. Which improved the efficiency of creation and inspired artists' creative inspiration. It also made learning and practice more convenient and made the division of labor and cooperation on artistic works possible.In the early Renaissance, artists were constantly exploring the improvement of techniques and painting materials. These changes subtly influenced the operation of studios. This paper will analyze the contribution of materials and techniques to the creation of artists and the development of studios from the two aspects of sketch and fresco.The evolution of sketching tools and the improvement of techniques provide more possibilities for the creation of artists. The change of paper and pen makes relevant work relatively easy. From drawing board to paper, the artist's design concept and way of design are more open. From the silver stylus to the dipping pen and chalk, the artist's technique has been improved and the quality has increased. As for the manuscripts in the fresco, from the early manuscripts on the wall to the appearance of the grid drawing technique, to the use of Cartoon, a large sketch. This progress has played an important role in the formation of artists' design and division of labor in the studio.
\end{abstract}

Keywords: Renaissance, Materials, Techniques, Art studios, The sketch, The mural

\section{INTRODUCTION}

The Renaissance began in the 14th century and flourished in the 15 th and 16 th centuries. During the Renaissance, there emerged a large number of artists and artists' studios with the characteristics of The Times. Studios are commercial shops and art schools that teach apprentices. At the beginning of the Renaissance, copying and reproduction were so common that the consignor would even stipulate in the commission that the artist should refer to or imitate a work of art. In the studio, apprentices learn the master's style by copying the atlas and work together to complete the commissioned works of the studio. In these studios, materials and techniques become their distinctive and unique, but also important creative support for them.

Materials and techniques have a significant influence on artists' creations. Any art needs corresponding techniques as the basis, material differences will bring about the difference in the specific operation and practice. Only after mastering the techniques can we express our understanding of art and show our artistic skills in practice. Thompson mentioned that technique refers to the materials and tools used in practice, and the essence of technique learning is to recognize those systematic methods[1]. It is a combination of interest, knowledge, and skill, drawn from the individual experience of the profession. In Renaissance studios, teachers teach students about steps, methods, and how to use materials. Each step is tractable, not accomplished by the individual imagination of an art student[2].

It can be seen that the development and innovation of materials and techniques are of great significance to the creation of artists and the development of studios. This paper will start with two different artistic ways of sketch and fresco, and make an in-depth analysis of their materials and techniques. 


\section{IN THE STUDIO SKETCH LEARNING PROCESS OF MATERIAL CHANGE AND TECHNICAL INNOVATION}

According to Baxandall, the sketch in the middle ages is only as an auxiliary tool, and during the Renaissance, the collector's focus began to shift from the precious pigments of the original commission to the individual techniques of the artist[3]. Therefore they identify with sketches, like frescoes and easel paintings, had an independent artistic value. Also, studio apprentices learning to paint have to begin by copying[2].

A panel is an important tool for the apprentice training sketch technique. In the early Renaissance, before the popularity of paper as a medium for painting, painters often used parchment, which is expensive and cumbersome to use[4]. At this time, copybooks made of parchment were one of the important properties of a studio. During this period, the panel, also an important property of the studio, played an important role in the training of apprentices and the spontaneous exploration of the artist drawing. Cennini described how to make a qualified panel in his book of art "How to begin to paint pictures". The panel made of willow wood and boxwood chips is spread out with a thin layer of bone powder as the base. The apprentices work with the silverpoint to practice drawing on the panel. A special advantage of using the panel is that the base can be scraped off for the apprentices to draw again[4].

Panels facilitate the practice of the apprentice, while paper gives the artist a new passion for creation and design. Although in the 15 th century, the price of highquality paper was one-sixth that of parchment[5], for artists, the greater reason for using paper was the creative freedom it brought. Paper enables artists to spontaneously explore painting for no practical purpose. Paper not only provides artists with a medium for creative artistic expression but also stimulates their demand for artistic innovation as a tool for artists to explore art. The use of paper not only provided convenience for artists' creation but also increased the number of collected sketches from the late 15 th century. Sketches gradually changed from auxiliary tools that could be recycled and destroyed to works with independent artistic value and collection value[6].

Except for copybooks and panels, the silverpoint is also an important property of a studio. Cennini argued that the apprentice should begin his apprenticeship by sketching, and only after mastering these skills could he go on to learn how to paint on boards (tempera) and walls (frescoes)[4]. He suggested starting with using silverpoint, which is not easy for beginners to grasp and requires patience, control, and discipline, but as part of the studio apprenticeship, the rigour of the course can be beneficial[4]. However, the silverpoint is difficult to control, the lines cannot be modified, and the lines are drawn without thickness or depth of color, making it difficult to produce texture effects. Artists from techniques and tools to carry out innovation. In terms of techniques, by adding lead white pigments to salience the highlight, the gray background is used as the middle tone. Generally, the dark part is drawn with silvertip first, and then the light part is drawn with the brush head. Makes the picture present more obvious black, white, and gray tones. The painter's pursuit of black, white, and gray tones has much to do with the importance of light and shade in painting emphasized by Alberti in "On Painting". The use of the lead white highlighter technique has brought the painting step by step closer to the peak of glory. On tools, dip pens, and chalk have brought innovation. Studio apprentices were able to use dip pens, usually quills, once they were familiar with the silverpoint. Quill pens can be cut into different shapes according to specific needs. The thickness of the pen tip can be cut into different degrees according to the requirements of the picture. It can shape rich lines to show the texture and material of objects, which is more flexible than the silvertip pen. But dip pens also don't show color changes. In the late fifteenth century, the use of chalk gained widespread acceptance. It satisfies the artist's need to express light and color changes in their sketches[7]. Da Vinci used red chalk in his painting, which shows the variation of light, shade, and color.

\section{MATERIAL CHANGE AND TECHNICAL UPGRADE IN MURAL DESIGN AND CREATION}

Before the middle of the fifteenth century, manuscripts of frescos were painted in sinopia directly on the walls. Sinopia is a naturally occurring mineral form of iron oxide called hematite, which in its powdery form was used as a pigment and was suitable for frescoes and tempera. Since this red clay pigment was often used in the drawing manuscripts of frescoes, it came to refer specifically to the manuscript itself. The specific steps are as follows: before the final layer of intonaco is applied to the fresco, sinopia is used to draw the outline on the fresco intonaco[8].

After the painter had finished the preparation of shaping on the wall with a charcoal pen, the painter used sinopia and brush head to make the manuscript of the fresco. The main problem with this technique, however, is that it is not painted on the last coat of intonaco. The intonaco hydrates for only 12-24 hours. After that time, the intonaco stops absorbing pigments, so the painter and his assistants can only work in a small area each day. Moreover, when the painter finished the manuscript with sinopia, he (or her) directly cover it with intonaco and finished it piece by piece, just like a patch, while it was still wet. Therefore, the painter could not see the manuscript at all in the process of painting. It only provided the painter with a general outline and position, 
while the specific details and performance could not help the painter.

Around 1420, when Masaccio painted the famous "the Holy Trinity", he used the method that Renaissance architects to solve the problem of perspective and proportion. The head and body of the Virgin Mary were cut by several square grids to determine the proportion and position. The method is called the grid technique. Divide the drawing into accurately measured squares. The canvas or wall is also drawn in the same number of squares. Each square on the drawing is copied by hand onto its corresponding large square, and the amount of detail that can be accommodated depends on the number of squares a person initially chooses[8].

It is of great significance for artists and studios to solve the problem of shortening perspective to the greatest extent and means that more people can be involved in the creation of artistic works, especially large murals, at the same time. In fact, in later art studios, such a division of labor can be further refined. Masters create the initial small manuscript and then cut the same proportion of small square grids. After the grid is divided, assistants or apprentices transfer the manuscript to the wall, and the division of labor makes the painting of different areas. This approach is a far cry from the early 15 th-century artists, who expected pictures to be transferred from small, highly finished sketches to walls. It was not until the late fifteenth century that painters generally realized that the use of the grid to determine proportion and composition from the overall perspective of the picture could best offset the shortcomings of only seeing parts.

It is worth mentioning that in the composition of the Holy Trinity, Massaccio USES Brunelleschi's architectural perspective rule to cut the outline of the building directly on the plaster layer with a sharp needle. He first constructed the perspective space within the image using pointed needles and then detailed each individual object, including a cone dome and an Ionian stigma with a distinct shortening of perspective. We can see that Masaccio used this method to try to construct a linear perspective of the arch and the whole space of the building, from which it is clear that he did not draw a sketch of the same size on the paper. It was not a bad thing that the fourteenth century's painters were more willing to resort to the tools of grid and needle scale to cope with the incomplete view of frescoes. Such attempts had positive implications for both the large sketches that appeared in the fifteenth century and for Spolvero's innovations. Because the artist could not see the manuscript during the process of painting, the 14th and early 15th-century sinopia manuscripts were usually made of simple Outlines. Painters of the time often relied on richly detailed and highly finished sketch forms (the head predominates) in their final frescoes. However, not all 14th-century Manuscripts of sinopia only have simple, auxiliary contour lines. Painters at that time had begun to realize the importance of sketch and were experimenting with it.

It was driven by the widespread use of sinopia to make more detailed and expressive sketches. By the second half of the fifteenth century, artists adopted a new way of making manuscripts. They began to use cartoons with the same size of frescos. A cartoon is made of many separate pieces of paper glued together, for example, the cartoon of Raphael's The School of Athens is made up of nearly 200 sheets of paper. There are two main ways to transfer a cartoon. The first method, known as spolvero, is to poke tiny holes in the outline of a large sheet of paper, then put the paper on the intonaco layer and punched along the holes with chalk or charcoal powder to transfer the outline. After that, the painter could paint with pigments. Michelangelo painted the Cappella Sistina's fresco in this way[9]. In this way, the sketch can be seen all the time, which greatly enhances the role of the sketch in the fresco. Also, due to a certain proportion of clay in chalk, it blends well with the intonaco layer, so that no trace of the sketch can be seen when the fresco is finished. The second method, which comes from the medieval tradition of copying, is more time-efficient for transfer. It is the artist who uses a pointed needle to draw chalk lines on the manuscript, leaving marks on the stucco layer beneath[8].

The grid technique and the use of cartoons have great significance to a productive studio. This is conducive to the division of labor of the studio in the completion of the work, the painter does not need to do the whole painting, but can work with assistants and apprentices at the same time in different parts or different stages of creation. This not only improves efficiency but also greatly improves the quality of the work.

\section{CONCLUSION}

The development of materials and techniques during the Renaissance is of great significance. In the creation of painters, the innovation of materials and techniques provides more convenient approaches and more diversified painting forms, which stimulates the creative enthusiasm of artists. In terms of its influence on the studio, the studio is a shop, workshop, and school. The development of materials and techniques first facilitates the learning and practice of apprentices, making them more effective in assisting the masters. And in the creation of frescos and other works of art, the progress of techniques also prompted the studio to form a more clear division of labor.

\section{REFERENCES}

[1] Thompson, 1956: Daniel V. Thompson, The materials and techniques of medieval painting, New York: Dover, 1956. 
[2] Cao, 1999: Cao Yiqiang, 'Artistic media and creative intention', Art Research, 4, 1999, pp. 3-5

[3] Baxandall 1974: Michael Baxandall, Painting and experience in fifteenth century Italy : a primer in the social history of pictorial style, NewYork : Oxford University Press, 1974.

[4] Cennini, 2015: Cennino Cennini, The Book of the Art (trans by Christiana J.Herringham), London: George Allen/Ruskin House, 1899. Bambach, 1999: Carmen C.

[5] Huizinga, 1997: Johan Huizinga, The Waning of the Middle Ages, Beijing: China Academy of Art Press.

[6] Brudet, 1982: G A Brudet, Florence during the Renaissance(trans by Zhu Longhua), Hongkong: SDX Joint Publishing Company.

[7] Bambach, Drawing and painting in the Italian Renaissance workshop: theory and practice, 13001600, New York : Cambridge University Press, 1999.

[8] Mayer, 1990: Ralph Mayer, The Artists handbook of materials and techniques, Nanning: Guangxi Art Publishing House, 1990

[9] Cole, 2014: Michael W. Cole, Leonardo, Michelangelo, and the art of the figure, New Haven Yale University Press, 2014.

[10] Ames-Lewis, 1999: Francis Ames-Lewis, Drawing in early Renaissance Italy, London: Yale University Press, 1999. 